\title{
Factors Affecting Catch-and-Release Mortality of Bluefish
}

\author{
MARY C. FABRIZIO* \\ Department of Fisheries Science, Virginia Institute of Marine Science, \\ Post Office Box 1346, Gloucester Point, Virginia 23062, USA
}

FREDERICK S. SCHARF

Department of Biology and Marine Biology, University of North Carolina-Wilmington, 601 South College Road, Wilmington, North Carolina 28403, USA

\section{GARY R. SHEPHERD}

National Oceanic and Atmospheric Administration Fisheries, Northeast Fisheries Science Center, Woods Hole Laboratory, 166 Water Street, Woods Hole, Massachusetts 02543, USA

\section{JoHn E. RosendALE}

National Oceanic and Atmospheric Administration Fisheries, Northeast Fisheries Science Center, James J. Howard Marine Sciences Laboratory, 74 Magruder Road, Highlands, New Jersey 07732, USA

\begin{abstract}
Recreational harvests of bluefish Pomatomus saltatrix along the U.S. coast from Maine to Florida exceed commercial harvests, and in recent years about $60-70 \%$ of angler-captured fish are released alive. The proportion of fish that survive hooking, handling, and release back to the ocean is unknown; however, if catch-and-release mortality is high, it may represent a significant component of the overall bluefish mortality rate. We estimated long-term (21-d) hooking mortality rates of field-captured bluefish and investigated the effects of various factors on postrelease mortality. Age, length, and the occurrence of bleeding were significant factors associated with catch-and-release mortality, which we estimated to be $38.8 \%$. About $65 \%$ of the mortality was initial mortality, and the remainder was delayed mortality. We also performed a laboratory study to examine the physiological response of bluefish to two independent processes (hooking and release versus transfer in coolers to the laboratory) relevant to the field study. Laboratory-held fish that were hooked and released exhibited elevated concentrations of potassium in their blood, suggesting that they experienced either an osmotic imbalance or cellular damage. Laboratory-held fish exposed to the transfer treatment only exhibited osmotic imbalance (elevated plasma sodium concentration) and evidence of anaerobic metabolism (elevated plasma lactate concentration). Our findings indicate that bluefish age and size contribute to variable levels of metabolic stress and that delayed postrelease mortality is considerable.
\end{abstract}

Atlantic coast bluefish Pomatomus saltatrix are sought by recreational anglers and commercial fishers from Maine to Florida. Landings from recreational fisheries exceed those from commercial fisheries (Figure 1), but the proportion of landings attributed to recreational anglers has been declining. During the 1980 s, about $80-85 \%$ of the total bluefish landings by weight were taken by recreational anglers; more recently (2000-2004), this percentage has decreased to $69-74 \%$. The Atlantic coast bluefish fishery is managed using an annual total allowable catch (TAC), which is partitioned into commercial and recreational quotas. The annual TAC for bluefish is based on biomass estimates from a forward catch-at-age model, which assumes that if released, fish captured by hook and line experience $15 \%$ postrelease mortality. If the

\footnotetext{
* Corresponding author: mfabrizio@vims.edu
}

Received February 22, 2007; accepted July 2, 2007 Published online March 31, 2008 catch-and-release practice among bluefish anglers is insignificant, then the assumption of $15 \%$ postrelease mortality introduces only a minor bias in the TAC estimates. However, in recent years, a rather large proportion-about $60-70 \%$ - of bluefish from Maine to Florida has been released by recreational anglers (Figure 2; National Marine Fisheries Service, Fisheries Statistics Division, unpublished data). This pattern of increasing recreational releases has been observed in many other marine species (Bartholomew and Bohnsack 2005).

Although the motivation for releasing bluefish is unknown, increases in the number of released fish may be associated with the imposition of size limits in Georgia, Florida, and Maryland, or with the 1999 coastwide possession limit (bag limit $=10$ fish in most states, 3 fish in Maine, and 15 fish in New Jersey and Georgia). In addition, many anglers practice catch-andrelease fishing in an effort to contribute to the conservation and long-term sustainability of fish stocks. 


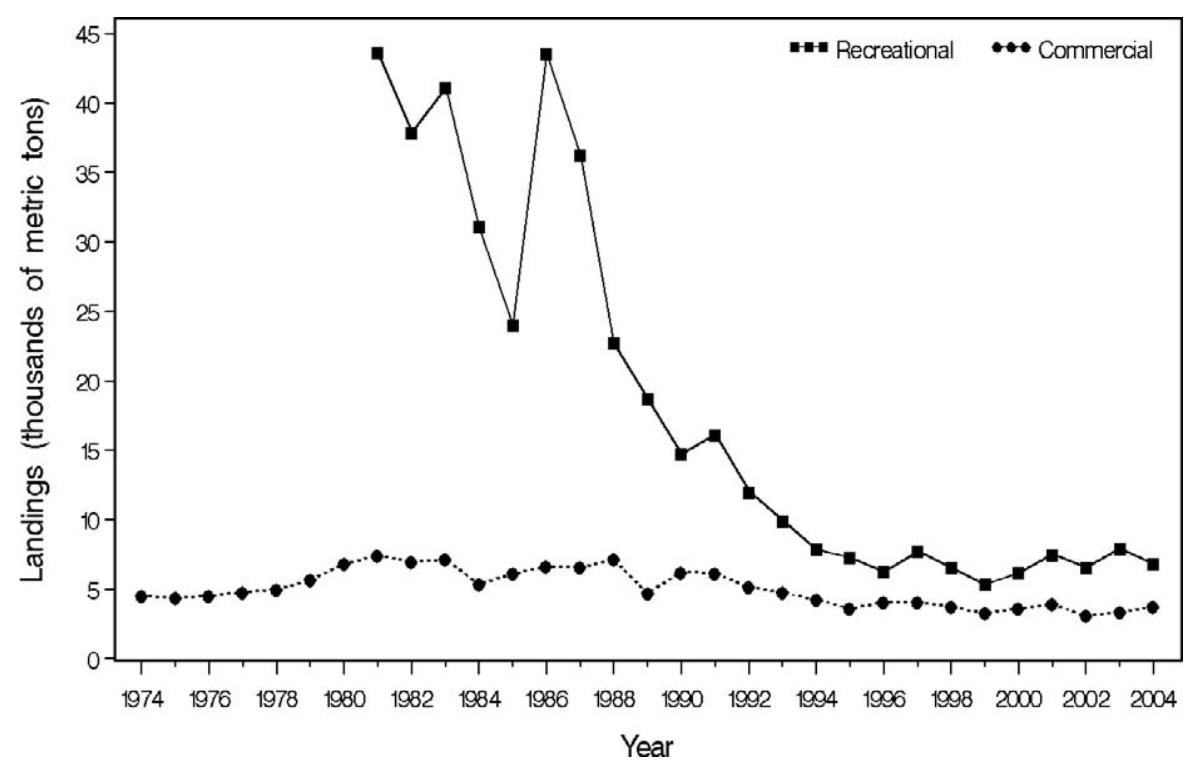

FIGURE 1.-Commercial (circles) and recreational (squares) fishery harvests of Atlantic coast bluefish during 1974-2004 (NEFSC 2005).

Recent data from the Marine Recreational Fishery Statistics Survey indicate that the proportion of bluefish released by recreational anglers varies by mode of fishing (Table 1). Most (95\%) of the total catch (retained + released fish) are taken by anglers fishing from shore and on private or rented boats, and these groups released considerably more bluefish than they retained.
To date, only a few studies have been conducted on postrelease mortality of angled bluefish (Malchoff 1995; Williams 1995; Ayvazian et al. 2002), and these studies indicate that short-term survival (up to $7 \mathrm{~d}$ postrelease) is fairly high. For instance, Ayvazian et al. (2002) reported 95\% survival after 2 h, Malchoff (1995) observed $87.6 \%$ survival up to 3 d postrelease,

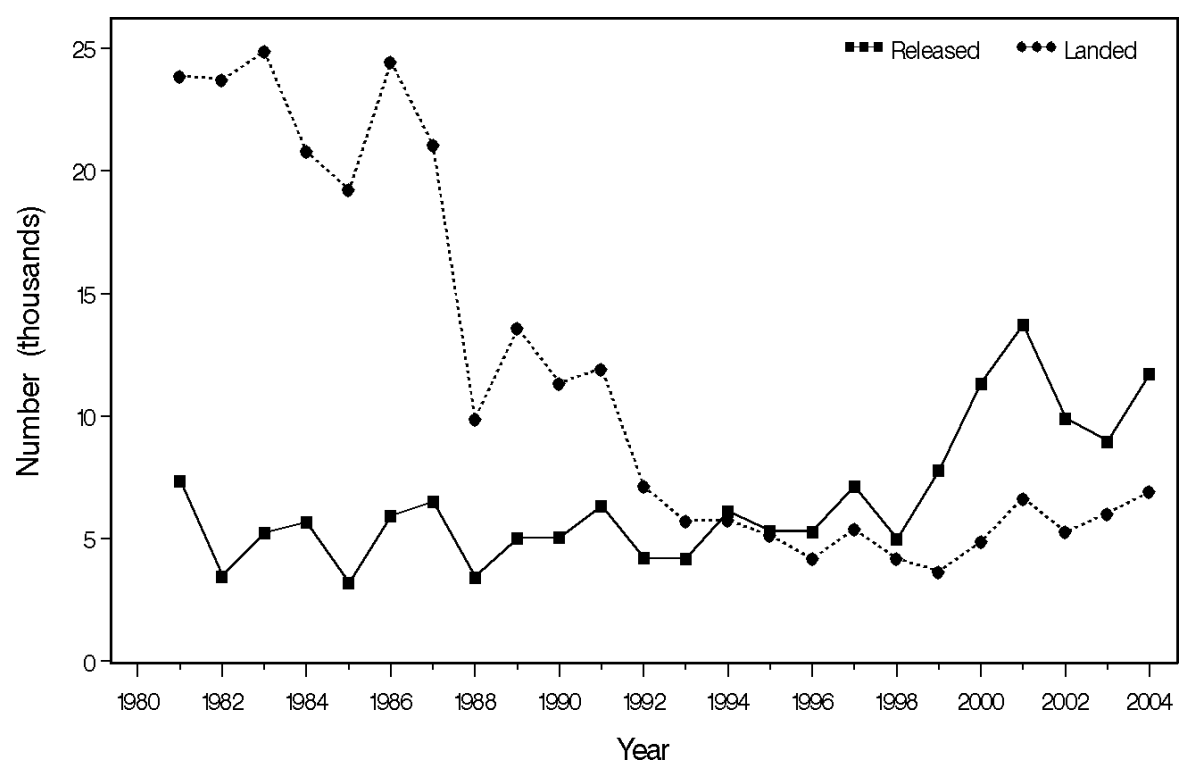

Figure 2.- Number of bluefish landed (circles) and released (squares) by recreational anglers along the Atlantic coast during 1981-2004 (National Marine Fisheries Service, Fisheries Statistics Division, unpublished data). 
and Williams (1995) reported $97 \%$ survival in jawhooked fish but only $68.7 \%$ survival for gut-hooked fish observed for $7 \mathrm{~d}$. Although postrelease mortality in bluefish appears to be relatively low (compared with rates reported by Muoneke and Childress [1994] and Bartholomew and Bohnsack [2005]), previous studies may have underestimated total mortality associated with capture and release because postrelease observation times were short.

What is a sufficiently long postrelease observation period? A review of catch-and-release mortality studies concluded that most mortality occurs within $24 \mathrm{~h}$, but a more complete estimate of the mortality should include delayed mortality (i.e., that occurring beyond the first $24 \mathrm{~h}$ postrelease; Muoneke and Childress 1994). Typically, a 3-d observation period is used (e.g., see Matlock et al. 1993; Malchoff and Heins 1997), and only a few catch-and-release mortality studies use a longer postrelease observation period (e.g., blue cod Parapercis colias were observed for $14 \mathrm{~d}$ : Carbines 1999; largemouth bass Micropterus salmoides for 1421 d: Schramm et al. 1987; spotted seatrout Cynoscion nebulosus for $30 \mathrm{~d}$ : Stunz and McKee 2006; white seabass Atractoscion nobilis for $90 \mathrm{~d}$ : Aalbers et al. 2004; and white crappies Pomoxis annularis for 18 months: Colvin 1991). Observations beyond $3 \mathrm{~d}$ are difficult because fish must be confined artificially either in the laboratory or in the field, and such confinement may contribute to further stress and mortality.

Short periods of observation (e.g., up to 3 d) after release may be sufficient for determining mortality due to acute effects (e.g., blood loss from hook wounds: Carbines 1999). However, delayed mortality may result from physiological disturbances (stress) from which a fish may not be able to recover (Wedemeyer et al. 1990). For example, physical trauma (e.g., lesions and disease resulting from hook damage) may lead to delayed postrelease mortality (Borucinska et al. 2001). Alternatively, capture and handling may lead to compromised osmoregulation or may involve irreversible cellular or tissue damage. Another source of delayed mortality in fish is immunological suppression (Lupes et al. 2006). Regardless of the cause, delayed mortality could represent a significant proportion of total postrelease mortality. In largemouth bass, about $33 \%$ of the total mortality was delayed (Schramm et al. 1987). Although fish may appear healthy and vigorous when released, hooking wounds, disease, and other stresses may contribute to delayed death (Muoneke and Childress 1994; Olla et al. 1997).

Several factors are associated with increased postrelease mortality in fish. Based on a meta-analysis of 53 catch-and-release studies, hooking location, use of
TABLE 1.-Percentages of bluefish retained and released by marine recreational anglers along the Atlantic coast, 20002004 (National Marine Fisheries Service, Fisheries Statistics Division, unpublished data).

\begin{tabular}{lcc}
\hline \multicolumn{1}{c}{ Mode of fishing } & Percent retained & Percent released \\
\hline Charter boats & 72.7 & 27.3 \\
Party-charter boats & 74.1 & 25.9 \\
Private-rental boats & 32.3 & 67.7 \\
Shore anglers & 33.4 & 66.6 \\
\hline
\end{tabular}

natural bait, depth of capture, elevated water temperature, and extended playing and handling times were significantly associated with increased hooking mortality rates across species (Bartholomew and Bohnsack 2005). In bluefish, the location of the hook wound is an important determinant of catch-and-release mortality (Ayvazian et al. 2002). Adult bluefish hooked in the gut or gills and observed for $2 \mathrm{~h}$ postrelease were concluded to have died because of the increased handling time required to remove the hook from the fish (Ayvazian et al. 2002). Bait type, fish size, and water temperature had no detectable effect on postrelease survival of bluefish monitored for $3 \mathrm{~d}$ (Malchoff 1995). When bluefish were observed for $7 \mathrm{~d}$ after release, hook wound location, fishing method, hook size, and hook type affected the survival rates (Williams 1995). Whereas these factors may be good predictors of short-term mortality, additional factors may contribute to delayed mortality.

In this study, we estimated mortality of bluefish that were captured by hook and line and observed for a 21-d period after release into laboratory aquaria. We also attempted to identify factors influencing postrelease mortality and investigated changes in various blood constituents associated with capture and handling. If the survival rate of released bluefish is considerably less than $85 \%$ (the current assumption), then the additional mortality due to catch and release should be incorporated into stock assessments for this species.

\section{Methods}

Postrelease mortality of field-captured bluefish.Based on our observations of bluefish angler habits and bluefish feeding behavior, we hypothesized that the following factors may affect postrelease mortality: (1) presence of bait, (2) handling technique, (3) amount of time the fish is on the line (retrieval time), (4) time out of water (i.e., air exposure duration), (5) hook location (jaw, throat, or gut), and (6) tissue damage (as evidenced by bleeding). We experimentally controlled for bait presence, handling technique, and air exposure duration, and we also observed retrieval time, hook location, and presence or absence of bleeding. We 
examined two other factors that were also not under our experimental control: fish age (determined from scale samples) and size. We tested either baited, single hooks (size 6/0, barbed) or artificial lures with single hooks because these represent gears used by the majority of bluefish anglers along the Atlantic coast. For each fish captured, we imposed one of two handling techniques that were intended to mimic handling procedures used by an experienced (good handling) and inexperienced angler (poor handling). The contrast in handling techniques addressed air exposure duration, amount of direct contact between the angler and each fish, and the general roughness of the handling process. Specifically, poor handling involved (1) exposing the fish to air for periods longer than $2 \mathrm{~min}$, (2) dropping the fish onto the deck of the boat, where it would struggle momentarily, and (3) handling the fish excessively with bare hands, causing disruption or partial loss of the mucous layer.

We captured 67 bluefish (mean total length [TL] = $71.5 \mathrm{~cm} ; \mathrm{SE}=1.00$ ) by hook and line during $3 \mathrm{~d}$ of sampling in November 2001 in New Jersey coastal waters at an average depth of $31.6 \mathrm{~m}$ and an average water temperature of $11.3^{\circ} \mathrm{C}$. After good ( $n=35$ fish) or poor ( $n=32$ fish) capture and handling were performed, fish were tagged with individually numbered anchor tags and placed in 1,500-L holding tanks supplied with flow-through seawater on board the sampling vessel. When the vessel returned to the dock, bluefish were transferred from the holding tanks to 120-L coolers to facilitate transfer to flow-through aquaria at the James J. Howard Marine Sciences Laboratory, Highlands, New Jersey. This transfer in coolers was brief (less than $30 \mathrm{~min}$ ). We recorded time elapsed between removal of the hook and placement of fish in a laboratory aquarium. Differences in fish size, time in shipboard or transfer tanks, retrieval time, and air exposure duration between the good and poor handling groups were tested using a Wilcoxon twosample test. We used a nonparametric test because these variables exhibited nonnormal distributions.

In the laboratory, we used several 2,400-L tanks and a single large research aquarium $(120,000 \mathrm{~L})$ to monitor survival of fish. During captivity, bluefish were given a diet of frozen fish. For fish that died during the 21-d observation period, we recorded mortality date, tag number, and TL. Similar data (except mortality date) were recorded for survivors. Scales were taken for subsequent age analysis from dead fish and from fish that survived until the end of the observation period. General condition of dead fish was also noted (e.g., presence of skin lesions or other gross abnormalities).

Statistical analysis of factors associated with post- release mortality in the field.-To determine the relation between survival and factors such as air exposure duration and fish size, the Cox proportional hazards model was fitted to the data. This modeling approach also allowed us to compare survival times between groups of fish (e.g., good and poor handling groups). The Cox proportional hazards model is a commonly applied regression technique for survival analysis and is suitable for censored, continuous time data (Collett 2003). In survival studies, censored data occur because the status (alive or dead) of the experimental subject (in our case, fish) after the observation endpoint (in our case, $21 \mathrm{~d}$ ) is unknown. Our data therefore contained some censored observations (i.e., those fish that survived at least until day 21). Ignoring the censoring will lead to biased estimates of survival (Selvin 1998). In general, the survivor function, $S(t)$, is

$$
S(t)=P(T \geq t),
$$

where $T$ is a random variable associated with survival time and $P(T \geq t)$ represents the probability that an individual survives beyond time $t$ (Collett 2003).

Hazard functions, another basic expression of survival, are an instantaneous measure of risk. The hazard function, sometimes called the hazard rate, is the risk of death at time $t$ (Collett 2003). Thus, large hazard rates imply small probabilities of survival. The hazard function, $h(t)$, is related to the survivor function by

$$
h(t)=-d / d t\left[\log _{e} S(t)\right]
$$

If two hazard functions, $h_{1}(t)$ and $h_{2}(t)$, are proportional, then

$$
h_{1}(t) / h_{2}(t)=c \text { and } S_{1}(t)=\left[S_{2}(t)\right]^{c},
$$

where the proportionality constant, $c$, is the relative hazard or hazard ratio (Selvin 1998; Collett 2003). With this model, $c$ can be estimated without specifying the form of the hazard function (e.g., exponential, Weibull, or any other distribution; Selvin 1998). However, the Cox proportional hazards model assumes that $c$ does not change with time and that the effects of the independent variables follow a parametric form (e.g., linear) that leads to estimation of model parameters, $\beta_{j}$. With three independent variables in the model $\left(x_{1}, x_{2}\right.$, and $\left.x_{3}\right)$, the hazard of death at time $t$ for the $i$ th fish can be written as

$$
h_{i}(t)=h_{0}(t) \exp \left(\beta_{1} x_{1 i}+\beta_{2} x_{2 i}+\beta_{3} x_{3 i}\right),
$$

where $h_{0}(t)$ is a baseline or average hazard function, which is simply the hazard function when all independent variables are set equal to their means or, in the case 
TABLE 2.-Descriptive statistics for a laboratory experiment examining bluefish physiological changes associated with capture and handling. Fish subjected to the hooking treatment were captured with baited hooks (size 6/0, barbed). The transfer treatment involved placement of fish in coolers for a brief duration. A subset of fish was sacrificed for blood sample collection; a few attempts to collect blood failed, and some blood samples coagulated upon collection.

\begin{tabular}{lrrr}
\hline & \multicolumn{3}{c}{ Group } \\
\cline { 2 - 4 } \multicolumn{1}{c}{ Variable } & Hooking & Transfer & Control \\
\hline$N$ & 29 & 30 & 10 \\
Mean size (mm; and $n$ ) & $323(8)$ & $324(9)$ & $323(6)$ \\
Number sacrificed for blood sample & 10 & 9 & 0 \\
Number of blood samples at start & 8 & 9 & 0 \\
Number observed for 21 d & 19 & 21 & 10 \\
Number (\%) of mortalities & $1(5.26)$ & $4(19.05)$ & $2(20.00)$ \\
Number sacrificed after 21 d & 12 & 13 & 7 \\
Number of blood samples at 21 d & 11 & 9 & 5 \\
\hline
\end{tabular}

of binary variables, set to zero (Collett 2003). The hazard model coefficients, $\beta_{j}$, are interpreted in a manner similar to those from a general linear model: a single unit increase in the variable $x_{j}$ leads to an expected multiplicative change, $\exp \left(\beta_{j}\right)$, in the relative hazard when the other $j-1$ variables are held constant.

To evaluate the effect of several explanatory factors on catch-and-release mortality, we used the Statistical Analysis System (SAS) procedure PHReg to fit the Cox proportional hazards model to our survival data (SAS Institute 1996). Estimates of $\beta$-values and associated SEs were obtained by the maximum likelihood method. We used a model building and selection strategy based on the hierarchic principle recommended by Collett (2003); this strategy allows variables to be entered into or excluded from the model subject to the results of likelihood ratio tests. These tests were conducted with nested models, and the value of the test statistic $\left(-2 \log _{e} L\right.$, where $L=$ likelihood) associated with each addition or exclusion was evaluated against a $\chi^{2}$ statistic with 1 df at a significance level of 0.10 (Collett 2003). Once the best model was identified, we examined the deviance residuals to identify outliers and the weighted Schoenfeld residuals to assess the validity of the assumption of the Cox proportional hazards model-namely, that $c$ does not depend on time (Collett 2003). If the hazard function is independent of time, then the weighted Schoenfeld residuals when plotted against survival time are expected to vary randomly about the horizontal line at zero. The significance of parameter estimates $\left(H_{0}: \beta=0\right)$ was tested using Wald's $\chi^{2}$ statistic (Collett 2003); the hazard ratio was also calculated $(\exp [\hat{\beta}])$.

Laboratory determination of capture and handling
effects.-In addition to field experiments, we performed a controlled laboratory experiment to permit examination of the physiological effects of capture and handling as manifested in the blood of bluefish. We also monitored the mortality of these fish after treatments. Because we wished to use fish that had not previously been exposed to capture by hook and line, we used a 200-ft beach seine to collect about 175 age-0 bluefish (about 20-25 cm TL) from Sandy Hook Bay during $6 \mathrm{~d}$ in September 2002. These fish were laboratory acclimated in 2,400-L tanks and given ad libitum rations of frozen fish through April 2003. Seawater temperature was maintained at $15^{\circ} \mathrm{C}$ to simulate offshore temperatures in the Middle and South Atlantic bights and to promote growth. Of the initial 175 fish in the collection, 95 died. A few of these individuals $(n=9)$ succumbed to a gill infestation by parasitic monogean flukes (probably Gyrodactylus spp.). After the parasites were detected in several individuals, we successfully treated fish with a series of exposures to a weak formalin solution for a 30-min period. The other mortalities were due to fish jumping out of the tanks, even though tanks were covered with mesh screening to prevent such losses. In May 2003, we subjected 69 of the surviving fish that were in good condition to one of three treatments: capture by hook and line $(n=29)$, transfer in coolers $(n=30)$, or no treatment (control fish; $n=10$; Table 2). During the experimental periods, bluefish continued to receive a diet of frozen fish. Fish were permitted to self-select for the capture treatment, and the remaining fish were randomly assigned to either the transfer or control treatment. All treatments occurred at a water temperature of $15^{\circ} \mathrm{C}$. Once fish were subjected to a treatment, they either were randomly placed in an identical, adjacent tank and monitored for mortality during a 21-d posttreatment period or were sacrificed to obtain a blood sample (see Table 2 and below). Bluefish in the capture treatment were captured by hook and line, tagged with individually numbered anchor tags, measured, and kept out of water for $2 \mathrm{~min}$. Fish in the transfer treatment were individually captured using a dip net after water levels in the aquarium were lowered to facilitate rapid capture. Fish were then tagged and measured, and up to five individuals were placed into a 120-L cooler, which was loaded onto a truck for a transfer trip that simulated the transfer procedure used during the field experiment. Control fish were also captured by dip net, tagged, measured, and placed directly into an observation tank. Once experimental treatments were completed, every observation tank included fish from all three treatments that were distinguishable by their tags.

In addition to observations on mortality, we obtained 
a physiological profile by examining blood constituents associated with stress, including lactate, glucose, several electrolytes, various proteins, and cortisol (Houston 1990). For some species, physiological measures may be good indicators of potential mortality (e.g., Olla et al. 1998; Moyes et al. 2006). Because we could not collect blood from bluefish without prolonged periods of handling (and therefore possibly contributing to additional stress), we followed the approach of Davis et al. (2001) and sacrificed a proportion of the fish from each treatment (10 fish from the hooking treatment and 9 fish from the transfer treatment) to permit collection of individual blood samples. Control fish were sampled for blood at the end of the 21-d observation period (Table 2).

About $2 \mathrm{~mL}$ of cardiac blood were collected with a 3-mL syringe and 22-gauge needle from the bulbous arteriosus of fish that were euthanized by severing the spinal cord (Houston 1990). The needle was removed from the syringe, and the blood sample was expelled from the syringe into multiple centrifuge tubes treated with lithium heparin. Blood samples were centrifuged (4,000 revolutions/min for $10 \mathrm{~min}$ ) at $4^{\circ} \mathrm{C}$, and the plasma from each fish was allocated to three collection tubes. One subsample (tube) was sent to a commercial veterinary laboratory for analysis of 14 plasma constituents (albumin [A], globulin [G], lactate dehydrogenase, alkaline phosphatase, creatine kinase, amylase, aspartate aminotransferase, cholesterol, uric acid, calcium, potassium, sodium, chloride, and glucose). Plasma in the second subsample was stored at $-80^{\circ} \mathrm{C}$ and later sent to the College of Veterinary Medicine, Cornell University (Ithaca, New York), for analysis of cortisol using a radioimmunoassay technique. The third subsample was immediately analyzed for lactate concentration using an enzymatic technique (Sigma). Lactate concentrations were converted from absorbance values at $540 \mathrm{~nm}$ determined by spectrophotometer using a standard absorbance-concentration curve for known lactate concentrations of 20,80, and $120 \mathrm{mg} / \mathrm{dL}$. Samples with an absorbance level above that of the $120-\mathrm{mg} / \mathrm{dL}$ lactate standard were diluted $1: 1$ and reanalyzed to ensure accuracy; the resultant lactate concentrations were multiplied by 2 .

Statistical analysis of capture and handling effects in the laboratory.-Mortality rates of laboratory-held fish were estimated as simple proportions (number of deaths/number in treatment group) and compared by use of the $Z$-statistic (Fleiss 1981). The null hypothesis $\left(H_{0}\right)$ tested was the lack of difference in the proportion of fish that died among the treatments (capture, transfer, and control); all pairwise comparisons were examined at an $\alpha$ level of 0.05 .

In addition to the 16 plasma constituents, we calculated total plasma protein $(A+G)$ and the $A: G$ ratio. We tested for differences in the mean values of each of the 18 plasma constituents among fish from the three treatments using analysis of variance (ANOVA) followed by Tukey's studentized range test to identify significant differences with an experimentwise error rate of 0.05 . We also examined changes in plasma constituents of fish exposed to hooking and transfer treatments by comparing mean values measured immediately after treatment and those measured $21 \mathrm{~d}$ later. This allowed us to (1) test the hypothesis that 21 $\mathrm{d}$ is a sufficiently long acclimation period for bluefish to exhibit significant changes in plasma constituents and (2) verify that these changes in plasma constituents occurred in the direction approaching the controls. In addition, we evaluated the hypothesis that mean blood constituent levels after $21 \mathrm{~d}$ in captured fish and transferred fish did not differ from those in control fish. These hypotheses were tested at a significance level of 0.05 using ANOVA conducted with the general linear model (GLM) procedure in SAS.

To further evaluate the physiological disturbance associated with capture or transfer, we performed a multivariate ANOVA (MANOVA) to test the $H_{0}$ of no difference in the mean response of fish from the three treatments (control, hooking, and transfer). In this test, we considered only the plasma constituents that varied significantly among treatment groups (as indicated by tests performed above). We used Pillai's trace as the test statistic for the overall MANOVA because it is a more robust statistic (Quinn and Keough 2002). Next, we subjected these plasma constituents to a canonical discriminant function analysis (Quinn and Keough 2002). This allowed us to represent our multivariate observations in two-dimensional space (canonical axes) and describe treatment-related changes in bluefish blood constituents relative to control fish blood. The MANOVA and canonical discriminant analysis were performed with the GLM and CanDisc procedures in SAS.

\section{Postrelease Mortality}

After $21 \mathrm{~d}$, the total mortality rate for bluefish captured during fall 2001 was $38.8 \%$ (26 deaths out of 67 fish; SE $=5.95 \%$ ). We captured almost twice as many fish with baited hooks $(n=43)$ as with artificial lures $(n=24)$. Most of the bluefish mortalities (17 of 26 fish, or $65.4 \%$ of the total observed mortalities) occurred on the day of capture. An additional nine fish died within 3 weeks of capture, and these mortalities generally were evenly distributed in time. Most of the observed mortalities occurred in what appeared to be healthy fish $(n=20)$, but a small group of fish $(n=6)$ 
TABLE 3.- Mean size and handling times for bluefish captured off the New Jersey coast in November 2001 and subjected to good and poor handling techniques (defined in text). Retrieval time is the duration for which the fish was on the line. The $Z$ statistic is the normal approximation for a Wilcoxon two-sample test (null hypothesis = no difference in fish size or times). Within the good handling group $(n=35), 24$ fish were captured with baited hooks and 11 with artificial lures. Within the poor handling group $(n=32), 19$ were captured with baited hooks and 13 with lures.

\begin{tabular}{lccccc}
\hline & \multicolumn{3}{c}{ Handling technique } & & \\
\cline { 2 - 3 } \multicolumn{1}{c}{ Variable } & Good & Poor & & & $P$ \\
\hline Mean fish size (mm) & 712.5 & 717.5 & -0.186 & $>0.05$ \\
Mean time in shipboard tanks and transport cooler (h) & 4.97 & 4.87 & -0.226 & $>0.05$ \\
Mean retrieval time (min) & 2.3 & 2.5 & 0.728 & $>0.05$ \\
Mean air exposure duration (min) & 1.4 & 2.5 & & 5.313 & $<0.05$ \\
\hline
\end{tabular}

had obvious external infections and abrasions. The onset of external infections occurred as early as $3 \mathrm{~d}$ after capture. Whether fish released by anglers develop external infections such as those we observed in captivity is unknown. However, such infections may be symptomatic of physiological stress. These infections occurred in areas of the body subjected to handling (around the caudal peduncle and along the midportion of the fish) and possibly resulted from localized loss of the protective mucous layer.

Fish subjected to good versus poor handling did not differ significantly in average body length (Table 3 ). Likewise, fish from the good and poor handling treatments did not have significantly different average holding times (total time in the holding tank and coolers) or retrieval times (Table 3). However, fish subjected to poor handling spent more time out of water (mean $=2.5 \mathrm{~min}$ ) than those subjected to good handling $($ mean $=1.4 \mathrm{~min}$; two-tailed test: $P<0.05$; Table 3$)$.

\section{Factors Associated with Postrelease Mortality}

A Cox proportional hazards model was fitted to bluefish survival times to examine the effects of handling technique, retrieval time, presence of bait, hook location, air exposure duration, bleeding, dropping, time spent in holding tanks and coolers, TL, and

TABLE 4.-Numbers of bluefish (by age-group) that did or did not exhibit bleeding after hook-and-line capture off the New Jersey coast in 2001; values in parentheses are body sizes (total length, mm). These fish were used to model the relation between survival and age (years), bleeding, or size.

\begin{tabular}{lccc}
\hline & \multicolumn{2}{c}{ Bleeding } & \\
\cline { 2 - 3 } Age & Absent & Present & Total $n$ \\
\hline 2 & $3(565-590)$ & $1(465)$ & 4 \\
3 & $5(515-730)$ & 0 & 5 \\
4 & $3(670-795)$ & $2(675-690)$ & 5 \\
5 & $8(670-770)$ & $2(690-780)$ & 10 \\
6 & $9(700-770)$ & $4(720-820)$ & 13 \\
7 & $4(720-820)$ & $3(730-780)$ & 7 \\
8 & $2(800-885)$ & 0 & 2 \\
\hline
\end{tabular}

age. Because some of these attributes were not recorded or available for all fish, the model selection process was based on 46 bluefish for which all variables were recorded (Table 4). Age, TL, and bleeding were selected for inclusion in the model describing postrelease mortality; the likelihood ratio $\chi^{2}$ test indicated that this model fit the data well $\left(\chi^{2}=\right.$ 18.779, df $=3, P<0.10$ ). An examination of the deviance residuals from this model indicated no apparent outliers. All of the negative deviance residuals were for censored data, but the magnitude of their deviance was not different from that of uncensored data. The weighted Schoenfeld residuals showed no trend or obvious pattern, indicating that the proportional hazard assumption was reasonable for these data.

The maximum likelihood estimate of the age coefficient $\left(\beta_{\text {age }}\right)$ was $-2.392(\mathrm{SE}=0.867)$, which was significantly different from zero $\left(\chi^{2}=7.606\right.$, $\mathrm{df}=$ $1, P<0.10)$. The estimated $\exp (\hat{\beta})$ for age was 0.091 . This ratio can be used to contrast mortality risks of different age groups for a given size (TL) and bleeding condition; an increase of 1 year in age results in a multiplicative decrease of 0.091 in the relative hazard. Alternatively, an increase of 1 year results in a $10.9 \times$ $(1 / \exp [\hat{\beta}])$ increase in the survival probability when size and bleeding condition are held constant. If an angler captures two fish of the same size but different ages (one of age 4 and another of age 5) and both fish are bleeding when released, then the age- 5 fish is $10.9 \times$ as likely to survive as the age- 4 fish.

For fish of a given age between 2 and 8 years, the proportional hazard model indicates that an increase of $10 \mathrm{~mm}$ in TL results in a $1.3 \times(\hat{\beta}=0.028, \mathrm{SE}=0.010$, $\left.\exp [\hat{\beta}]=1.03 ; 1.03^{10}=1.3\right)$ increase in the relative hazard (or probability of mortality). Thus, within an age-class and for a given bleeding condition, larger fish tend to experience a greater risk of mortality associated with hooking and handling (Figure 3). Similarly, for a given length and age-class, the presence of bleeding results in a $9.1 \times$ increase in the relative hazard (mortality; $\hat{\beta}=2.212, \mathrm{SE}=1.300, \exp [\hat{\beta}]=9.138$ ). 

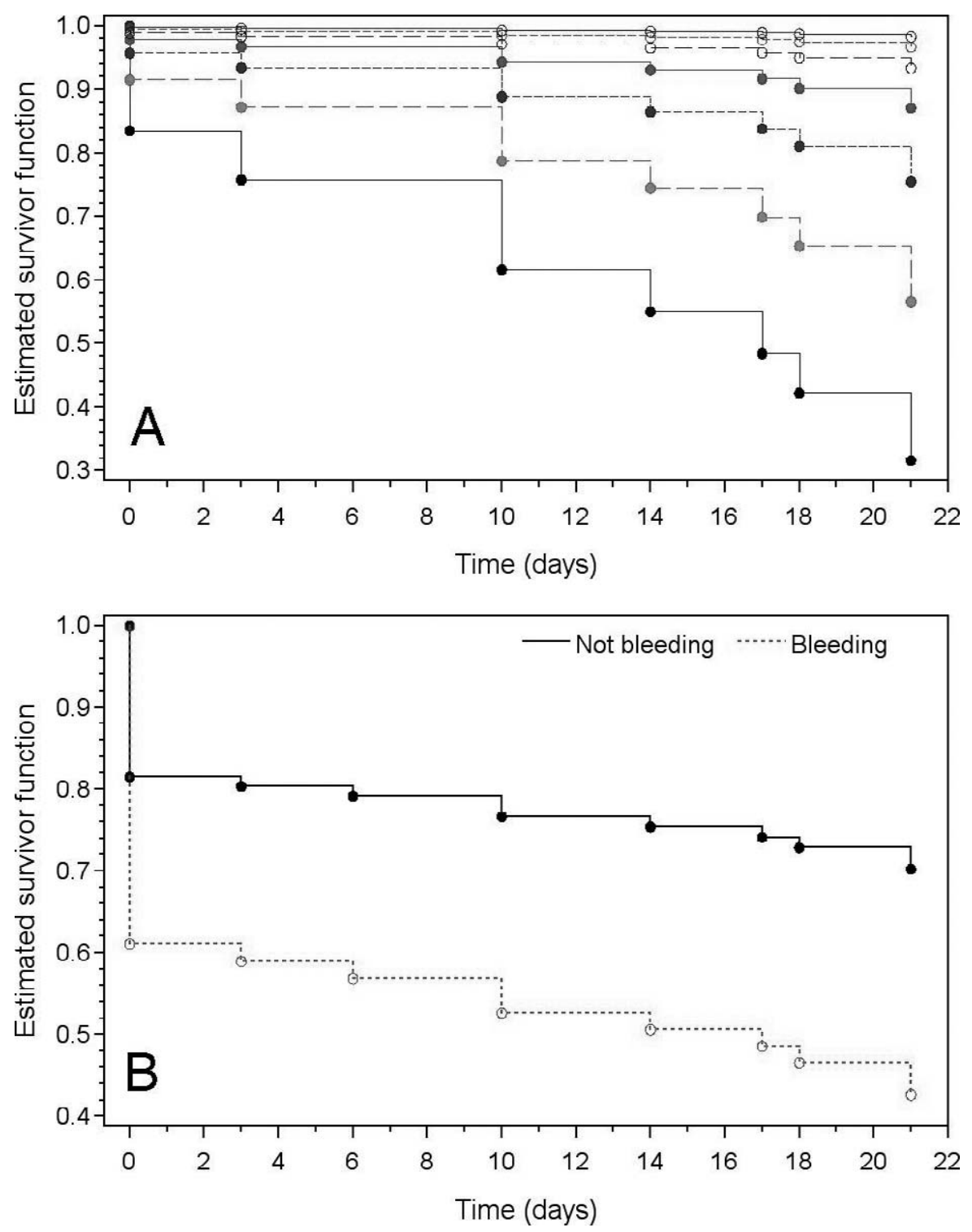

FIGURE 3.-Estimated survival functions for bluefish captured by hook and line and released in New Jersey coastal waters during November 2001; postrelease observation period was $21 \mathrm{~d}$ (the function evaluated at time $t$ is the probability that a fish will survive beyond time $t$ ): (A) survival function for ages 2-8 (size and presence or absence of bleeding are held constant; lowermost solid line $=$ age 2 ; uppermost line $=$ age 8 ), and (B) survival function based on presence or absence of bleeding (size and age are held constant).

Together, these model results imply that at a given size, the risk of mortality from catch-and-release fishing increases by $9-11 \times$ among (1 year) younger fish or when bleeding is present.

\section{Capture and Handling Effects}

Low but variable mortality rates were exhibited by the hooking treatment group (5.26\%), transport treat- ment group (19.05\%), and control group (20.0\%) during the 21-d posttreatment observation period. We could not detect a significant difference in posttreatment mortality among fish from the three groups (hooking versus control: $z=0.5976$; transfer versus control: $z=$ -0.4236 ; hooking versus transfer: $z=0.8383 ; P>$ $0.05)$. Fish appeared to recover from stressors associated with either the hooking or transport treatment alone. 
TABLE 5.-Mean (SE) concentrations of 16 blood constituents, total protein (albumin $[\mathrm{A}]+$ globulin $[\mathrm{G}]$ ), and A : G ratio in bluefish subjected to laboratory capture by hooking (capture, tagging, measurement, and 2-min air exposure); transfer by truck (dip-net capture, tagging, measurement, and holding in a 120-L cooler for trip); or control handling (dip-net capture, tagging, measurement, and placement into an observation tank).

\begin{tabular}{|c|c|c|c|c|c|c|}
\hline \multirow[b]{2}{*}{ Plasma constituent } & \multicolumn{3}{|c|}{ Group } & \multirow[b]{2}{*}{$\begin{array}{l}21 \mathrm{~d} \text { posthooking }{ }^{\mathrm{c}} \\
(n=11)\end{array}$} & \multirow[b]{2}{*}{$\begin{array}{c}21 \mathrm{~d} \text { posttransfer }{ }^{\mathrm{d}} \\
(n=9)\end{array}$} & \multirow[b]{2}{*}{$\begin{array}{l}\text { Moribund } \\
(n=3)\end{array}$} \\
\hline & $\begin{array}{l}\text { Hooking } \\
(n=8)\end{array}$ & $\begin{array}{l}\text { Transfer }^{\mathrm{a}} \\
(n=9)\end{array}$ & $\begin{array}{l}\text { Control }^{\mathrm{b}} \\
(n=6)\end{array}$ & & & \\
\hline \multicolumn{7}{|c|}{ Electrolytes } \\
\hline Calcium (mg/dL) & $10.7(0.521)$ & $10.1(1.129)$ & $12.9(0.647)$ & $13.4(1.003)$ & $12.0(0.322)$ & $12.6(3.285)$ \\
\hline Chloride (meq/L) & $145(1.464)$ & $140(1.811)$ & $139(3.449)$ & $137(5.596)$ & $142(2.402)$ & $138(13.614)$ \\
\hline Potassium (meq/L) & $6.5(0.190)$ & $5.1(0.217)$ & $5.1(0.221)$ & $5.6(0.405)$ & $5.1(0.206)$ & $6.9(0.968)$ \\
\hline Sodium (meq/L) & $177(0.773)$ & $188(2.195)$ & $177(3.480)$ & $191(8.411)$ & $182(2.170)$ & $191(7.768)$ \\
\hline \multicolumn{7}{|c|}{ Sugars } \\
\hline Glucose (mg/dL) & $129(6.425)$ & $222(35.679)$ & $200(20.197)$ & $187(14.656)$ & $189(14.447)$ & $340(247.272)$ \\
\hline Lactate $(\mathrm{mg} / \mathrm{dL})$ & $24.67(2.260)$ & $128.29(12.323)$ & $43.97(11.030)$ & $68.26(11.175)$ & $47.90(11.141)$ & $96.82(81.947)$ \\
\hline \multicolumn{7}{|c|}{ Proteins-enzymes } \\
\hline Albumin $(\mathrm{g} / \mathrm{dL})$ & $1.1(0.081)$ & $1.3(0.120)$ & $1.2(0.132)$ & $1.4(0.078)$ & $1.1(0.071)$ & $0.7(0.348)$ \\
\hline Alkaline phosphatase (IU/L) & $14(2.044)$ & $19(2.539)$ & $11(1.856)$ & $18(2.512)$ & $15(1.777)$ & $12(8.253)$ \\
\hline Amylase (IU/L) & $24(3.840)$ & $20(4.943)$ & $27(8.150)$ & $30(3.477)$ & $17(2.749)$ & $7(5.365)$ \\
\hline Aspartate aminotransferase (IU/L) & $136(52.698)$ & 57 (24.102) & $90(43.570)$ & $97(35.958)$ & $37(11.081)$ & $61(19.502)$ \\
\hline Creatine kinase (IU/L) & 391 (119.902) & $400(63.655)$ & $427(323.484)$ & $420(147.031)$ & $125(23.158)$ & $874(603.353)$ \\
\hline Globulin $(\mathrm{g} / \mathrm{dL})$ & $2.7(0.075)$ & $2.7(0.672)$ & $3.2(0.484)$ & $3.7(0.219)$ & $3.0(0.201)$ & $1.8(0.991)$ \\
\hline Lactate dehydrogenase (IU/L) & $275(88.031)$ & $312(67.602)$ & $288(113.398)$ & $124(37.408)$ & 49 (12.923) & $83(38.040)$ \\
\hline Total protein $(\mathrm{g} / \mathrm{dL})$ & $3.8(0.146)$ & $4.0(0.762)$ & $4.5(0.612)$ & $5.0(0.285)$ & $4.2(0.265)$ & $2.4(1.338)$ \\
\hline A : $\mathrm{G}$ ratio & $0.40(0.019)$ & $0.59(0.079)$ & $0.38(0.037)$ & $0.38(0.018)$ & $0.37(0.017)$ & 0.37 \\
\hline \multicolumn{7}{|c|}{ Other } \\
\hline Cholesterol (mg/dL) & $374(13.671)$ & $323(45.987)$ & $435(58.564)$ & $441(28.927)$ & $382(33.862)$ & $262(171.902)$ \\
\hline Cortisol (ng/mL) & $23.5(12.393)$ & $248.0(103.127)$ & 277.5 (107.071) & $246.5(56.051)$ & $140.2(55.194)$ & $348.6(221.972)$ \\
\hline Uric acid $(\mathrm{mg} / \mathrm{dL})$ & $0.2(0.019)$ & $0.6(0.134)$ & $0.5(0.136)$ & $0.4(0.073)$ & $0.2(0.066)$ & $1.5(1.301)$ \\
\hline
\end{tabular}

Mean levels of potassium, sodium, glucose, lactate, A : $\mathrm{G}$ ratio, cortisol, and uric acid in bluefish plasma varied significantly among fish in the control, hooking treatment, and transfer treatment groups (Tables 5, 6). The remaining plasma constituents did not show significant differences (Table 6). Fish subjected to the hooking treatment had significantly higher mean levels of potassium than did control fish, whereas fish subjected to the transfer treatment had significantly higher mean levels of sodium and lactate than did control fish (Tukey's studentized range test: $\mathrm{df}=20, P$ $\leq 0.05)$. We note that three moribund fish also exhibited mean concentrations of potassium, sodium, and lactate that tended to be higher than those of control fish, although this comparison was not tested statistically because of small sample sizes (Table 5). Elevated levels of individual blood electrolytes, such as potassium and sodium, may be indicative of an osmotic imbalance in fish and may be associated with acute or chronic stress (Wedemeyer et al. 1990). Alternatively, such imbalances may result from direct cellular damage. Fish in both the hooking and transfer treatment groups exhibited significant hemoconcentration of ions. For fish in the hooking treatment, elevated concentrations of ions may reflect a stress response, cellular damage during capture, or both. Elevated blood lactate levels indicate anaerobic metabolism, a response associated with shock (fright) or severe exertion (Wedemeyer et al. 1990), and fish in the transfer treatment may have experienced both conditions. We observed hyperactivity of fish in the transfer treatment group as they struggled to escape from the confined space of the cooler. Fish in the transfer treatment had significantly greater concentrations of glucose and uric acid than those in the hooking treatment, but neither treatment group differed significantly from control fish (Tukey's studentized range test: $\mathrm{df}=19, P \leq 0.05$ ). Although the mean $\mathrm{A}: \mathrm{G}$ ratio and mean cortisol concentration differed among the three treatments (Table 6), we failed to detect differences in means between treatment pairs (Tukey's studentized range test: $\mathrm{df}=19, P=0.05)$.

Plasma constituent concentrations that differed between control and treatment fish immediately after 
TABLE 6.-Results ( $F$-values) of an analysis of variance used to test the null hypothesis of no difference in mean plasma constituents among bluefish subjected to hooking or transfer treatments or control handling $(* P \leq 0.05)$. Total protein is the sum of albumin (A) and globulin $(G)$; the A : G ratio is also shown.

\begin{tabular}{lcc}
\hline \multicolumn{1}{c}{ Plasma constituent } & $\begin{array}{c}\text { Initial } \\
\text { samples }\end{array}$ & $\begin{array}{c}\text { 21-d posttreatment } \\
\text { samples }\end{array}$ \\
\hline & Electrolytes & \\
Calcium & 2.12 & 0.77 \\
Chloride & 2.39 & 0.28 \\
Potassium & $14.16^{*}$ & 0.94 \\
Sodium & $9.11^{*}$ & 1.20 \\
& Sugars & \\
Glucose & $3.62^{*}$ & 0.15 \\
Lactate & $34.36^{*}$ & 1.36 \\
& Proteins-enzymes & \\
Albumin & 0.76 & 2.34 \\
Alkaline phosphatase & 2.11 & 1.44 \\
Amylase & 0.32 & $3.43^{*}$ \\
Aspartate aminotransferase & 1.07 & 1.11 \\
Creatine kinase & 0.01 & 1.24 \\
Globulin & 0.25 & 1.75 \\
Lactate dehydrogenase & 0.06 & $4.76^{*}$ \\
Total protein & 0.24 & 1.99 \\
A : G ratio & $3.95^{*}$ & 0.16 \\
& & \\
Cholesterol & & \\
Cortisol & $4.83^{*}$ & 1.19 \\
Uric acid & & 2.14 \\
\hline
\end{tabular}

treatment (potassium in the hooking group, and sodium and lactate in the transfer group) were no longer significantly different from control values after $21 \mathrm{~d}$ (Table 6). The test for differences in mean plasma constituent levels between samples collected immediately after treatment and those collected at $21 \mathrm{~d}$ posttreatment provides further evidence that the 21-d observation period was sufficient to permit physiological acclimation in hooked or transported bluefish.

With two exceptions (amylase and lactate dehydrogenase), control fish and treatment fish sampled at $21 \mathrm{~d}$ posttreatment exhibited no significant difference in mean plasma constituent values (Table 6). Neither amylase nor lactate dehydrogenase differed among control, hooking treatment, and transfer treatment groups at the beginning of the experiment, indicating that these two constituents were not detectably different in fish exposed to the treatments. Therefore, differences observed among control fish and treatment fish measured after $21 \mathrm{~d}$ are probably spurious.

Physiological profiles based on plasma constituents tended to change by the end of the $21-\mathrm{d}$ period (Table 6); furthermore, the change was in the expected direction (i.e., toward control values). For fish in the hooking treatment, significant $(P<0.05)$ increases in mean plasma calcium $(F=4.61)$, glucose $(F=10.23)$, lactate $(F=10.67), \mathrm{A}(F=6.22), \mathrm{G}(F=12.09)$, total protein $(F=11.42)$, cortisol $(F=15.08)$, and uric acid $(F=5.41)$ were observed after $21 \mathrm{~d}$ (Table 5$)$. For fish in the transfer treatment, significant $(P<0.05)$ decreases in mean plasma concentrations after $21 \mathrm{~d}$ were observed for lactate $(F=23.42)$, creatine kinase $(F=16.44)$, lactate dehydrogenase $(F=14.56), \mathrm{A}: \mathrm{G}$ ratio $(F=7.58)$, and uric acid $(F=6.43$; Table 5$)$.

A MANOVA was performed with the seven plasma constituents (potassium, sodium, glucose, lactate, A : G ratio, cortisol, and uric acid) that individually differed significantly among bluefish from the three treatments. As expected, we found an overall significant difference in the mean concentrations of these constituents among treatments (Pillai's trace $=1.781$, approximate $F_{14,18}=$ $10.45, P<0.05)$. In addition, we tested the overall differences in mean values between control fish and fish in the hooking or transfer treatment (contrast statements in SAS). In both cases, mean values for hooking and transfer treatment groups differed significantly from those for control fish (hooking versus control: Pillai's trace $=0.854$, approximate $F_{7,8}=6.68$, $P<0.05$; transfer versus control: Pillai's trace $=0.903$, approximate $F_{7,8}=10.65, P<0.05$ ).

Canonical discriminant functions were estimated from 17 fish (control $n=4$; hooking $n=8$; transfer $n=$ 5) because 6 fish had missing values for one or more of the blood constituents analyzed. The contribution of each constituent to the canonical functions can be best assessed using the standardized canonical coefficients (Quinn and Keough 2002). Sodium, lactate, and, to a lesser degree, uric acid and glucose, contributed to the first canonical function. These blood constituents were characteristically high in transfer fish (Table 5), and thus the first canonical axis facilitated the separation of transfer treatment fish from control and hooking treatment fish (Figure 4). Potassium, lactate, and, to a lesser degree, uric acid and cortisol, contributed to the second canonical function. The second canonical axis facilitated the separation of control fish from the remaining fish (Figure 4). Bluefish blood constituents responded differently to the stress associated with catch and release and that associated with transfer, a difference clearly illustrated in the canonical plot (Figure 4). Fish in the transfer and hooking treatments had higher levels of electrolytes than did control fish, but the response profile of hooking treatment fish differed significantly from that of transfer treatment fish. Thus, it appears that the stress response in bluefish subjected to catch and release reflected osmoregulatory shifts, cellular damage, or both, whereas the stress response in transferred bluefish reflected changes in osmoregulation and anaerobic metabolism. 


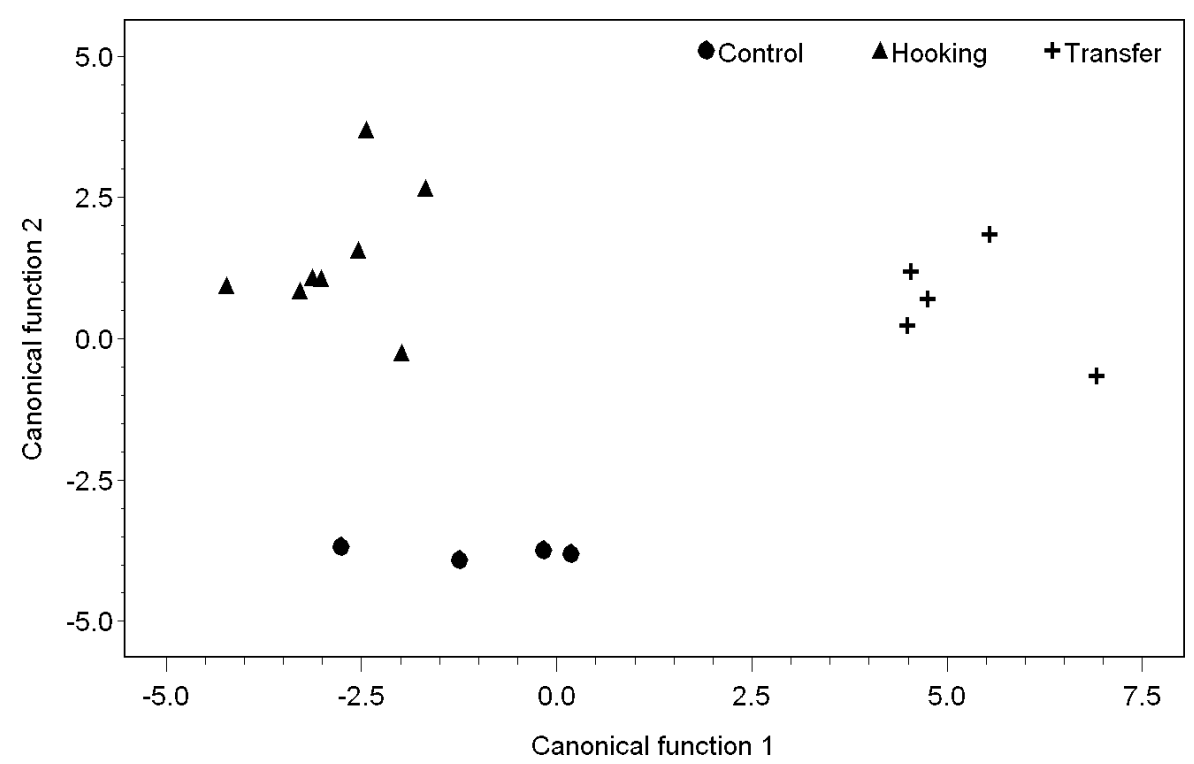

FIGURE 4.-Plot of canonical discriminant function scores from analysis of plasma constituents in bluefish subjected to a laboratory capture treatment (triangles; hook-and-line capture, tagging, measurement, and 2-min air exposure) or transfer treatment ("plus" symbols; dip-net capture, tagging, measurement, and holding in a 120-L cooler for a transfer trip by truck). Control fish (circles) were dipnetted, tagged, measured, and placed into an observation tank.

\section{Discussion}

Catch-and-release practices have become more common in marine recreational fisheries. Although the short-term survival rate of released fish is fairly well studied, long-term effects associated with cumulative mortality from multiple recapture events and disease or parasites are not widely known (Bartholomew and Bohnsack 2005). When available, postrelease mortality estimates can be incorporated into stock assessments, as was done for red drum Sciaenops ocellatus (Vaughan and Carmichael 2000). However, most estimates of postrelease mortality are based on short-term observations and thus provide estimates of initial mortality only. Our estimate of catch-and-release mortality in bluefish $(38.8 \%)$ was higher than previously reported estimates for this species. We believe this was due to our inclusion of delayed postrelease mortality: $65 \%$ of the mortality was initial mortality and $35 \%$ was delayed mortality. Use of initial mortality rates as the sole estimate of catch-and-release mortality for this species underestimates the true mortality associated with catch-and release fishing, because bluefish experience significant delayed mortality. We used a postrelease observation period of $21 \mathrm{~d}$, which was sufficiently long to allow plasma constituents of the surviving released fish to return to control levels. Thus, a 21-d period appears to be sufficient for detecting short- and long-term mortality in bluefish.
Age, length, and the occurrence of bleeding were significant factors associated with catch-and-release mortality in bluefish. The presence of bleeding significantly increased the risk of mortality, but not all fish that exhibited bleeding died. For a given ageclass and bleeding condition, smaller bluefish had a lower risk of postrelease mortality, implying that within a cohort, fish exhibiting slower growth rates tend to have higher survival rates from catch-andrelease fishing than faster-growing members of their cohort. Furthermore, for a given body size and bleeding condition, older fish had a significantly increased probability of survival than younger fish of the same size (a difference of 1 year in age confers a 10.9 times increase in the survival probability).

A meta-analysis of recreational angling studies indicates that the effect of body size on postrelease mortality is equivocal, with no general trend of increased survival for larger or smaller fishes (Bartholomew and Bohnsack 2005). However, this pattern may be due to the lack of studies that have explicitly tested for the effects of varying body size while controlling for other confounding factors (depth, bait type, gear, etc.). In contrast, studies of discard mortality in commercial trawl and longline fisheries demonstrates a clear pattern of survival for larger fishes across numerous species (Davis 2002). The increased mass of larger fishes is believed to minimize the effects of exposure to harsh temperatures during handling (Davis 
and Parker 2004) and enable quicker recovery from stress-related disturbance (Cooke et al. 2003). In addition, the scaling of standard weight-specific metabolic rate with size (Brett and Groves 1979) should provide larger fishes with increased metabolic scope to avoid exceeding metabolic limits during periods of high stress (Priede 1985). Our findings indicate that older and slower-growing bluefish will experience lower probability of mortality during catchand-release angling. The osmotic imbalance in hooked and handled fish, revealed by analysis of blood constituents, likely represents a considerable metabolic cost that may cause younger and faster-growing fish to exceed their metabolic limits, resulting in mortality. However, the physiological processes by which body size influences the postrelease recovery process in fishes are poorly understood (Kiefer 2000). Our observations imply that both size and age effects may be critical factors in understanding recovery from capture stress in bluefish.

Using a controlled laboratory experiment, we attempted to determine the physiological response of bluefish to two independent processes that affect catchand-release mortality. The first process, catch and release, was mimicked in the laboratory experiment by hooking fish that were originally captured with a beach seine and maintained in the laboratory for several months. The concentrations of several electrolytes, proteins, and enzymes in the blood of hooked fish were compared with those in the blood of control fish. We also simulated the process of transferring fish from the research vessel to the laboratory, where fish were maintained for postrelease observation. Although the transfer process was relatively quick, we were concerned that confinement during transfer would impose additional stress on fish. Neither the hooking treatment alone nor the transfer treatment alone resulted in mortality rates in excess of the rate observed among control fish, but this may be attributable to the small sample sizes used in this experiment. Small sample sizes are common, however, when relatively large fish are experimentally maintained for extended periods of time and physiological disturbances are studied (e.g., see Killen et al. 2006). Our laboratory experiment suggests that neither of these processes solely contributes to excess mortality and that handling (such as that experienced by the control fish) is sufficient to induce mortality. Although larger sample sizes could have permitted further testing for differences in mortality rate among these treatment groups, limited availability of fish and laboratory space makes this option impractical. Instead, other approaches, such as tagging studies (Hueter et al. 2006), may be fruitful areas of future research.
Our experimental results indicated that fish exposed to the transfer process exhibited increased concentrations of sodium and lactate relative to those in control fish. This response was different from that observed in hooked and released fish, which instead had elevated concentrations of potassium. In both processes, the osmotic balance of fish was compromised, but the proximate cause of the imbalance may arise from different stressors. In this respect, our results are similar to results reported for Pacific halibut Hippoglossus stenolepis, which also exhibited imbalances in different plasma constituents in response to different types of stressors (Davis and Schreck 2005). Bluefish subjected to the transfer process alone probably exhibited confinement shock, and their increased activity contributed to the observed anaerobic response (elevated plasma lactate concentration). Bluefish subjected to catch-and-release fishing exhibited osmoregulatory changes, cell damage, or both. Based on the observed plasma concentrations at the beginning and end of the 21-d observation period, fish that survive either of these processes appear to recover completely by $21 \mathrm{~d}$.

These laboratory tests suggest that field-captured bluefish experienced additional stressors during transfer to the laboratory for postrelease observation. The response of fish to the transfer process, however, appears to be different from the response to hooking and release. Fish seemed to recover completely from either stressor after $21 \mathrm{~d}$, but we do not know the magnitude of the additive effect, if any, of transporting released fish. Perhaps fish can recover from the catchand-release process, but the additional stress imposed by transfer to the laboratory may have contributed significantly to increased postrelease mortality. The trade-off is that initial mortality (such as may be observed by holding fish for a few hours) underestimates the total mortality associated with catch-andrelease fishing. Holding fish in laboratory aquaria or other confined spaces is one way of ensuring a sufficiently long postrelease observation period. However, this requires transferring fish from the point of capture to the holding facility, thus adding another stressor that might lead to increased mortality of fieldcaptured fish. We have captured bluefish by hook and line and transferred them to the laboratory for many previous experiments with good success; thus, we felt that the transportation method used in this experiment minimized additional stress to fish. Although the confinement for postrelease observations may impose additional stress on fish subjected to hooking and release, without such observations the total catch-andrelease mortality will be underestimated for species exhibiting delayed mortality. Experiments that mini- 
mize confinement stress during the postrelease period will yield the best estimates of total catch-and-release mortality.

\section{Management Implications}

The implication of this new estimate of catch-andrelease mortality depends on the behavior of recreational anglers. A discard mortality rate of $38.8 \%$ (SE $=$ $5.95 \%$ ) would imply that discard losses in recent years rival the number of bluefish harvested commercially. However, we do not know whether anglers will selectively retain damaged fish while releasing fish that appear healthy. Although our research shows that mortality cannot be predicted based on apparent injuries to the fish, this selective angler behavior could moderate the impact of discard mortalities on bluefish fisheries.

\section{Acknowledgments}

We thank Lt. S. Sirois and C. Brown (National Oceanic and Atmospheric Administration [NOAA] RV Gloria Michelle) and S. Fromm, J. Hilbert, S. Kiernan, J. Pessutti, R. Pikanowski, D. MacMillan, and J. McCarthy (NOAA Fisheries, Highlands) for assistance in the field. J. Burnett (NOAA Fisheries, Woods Hole, Massachusetts) determined bluefish ages, and $\mathrm{J}$. Samson, D. Wieczorek, and A. Draxler (NOAA Fisheries, Highlands) provided guidance and loaned us equipment to perform blood collections and analyses. A. Drohan (NOAA Fisheries, Highlands) and Z. Chenitz (volunteer) assisted with blood sampling and data management. R. Brill (Virginia Institute of Marine Science, Gloucester Point) and P. Bushnell (Indiana University, South Bend) provided helpful advice and information on collecting blood from bluefish and measuring stress indicators in fish. This paper is Contribution Number 2841 of the Virginia Institute of Marine Science, The College of William and Mary. Reference to trade names does not imply endorsement by the U.S. Government.

\section{References}

Aalbers, S. A., G. M. Stutzer, and M. A. Drawbridge. 2004. The effects of catch-and-release angling on the growth and survival of juvenile white seabass captured on offset circle and J-type hooks. North American Journal of Fisheries Management 24:793-800.

Ayvazian, S. G., B. S. Wise, and G. C. Young. 2002. Shortterm hooking mortality of tailor (Pomatomus saltatrix) in Western Australia and the impact on yield per recruit. Fisheries Research 58:241-248.

Bartholomew, A., and J. A. Bohnsack. 2005. A review of catch-and-release angling mortality with implications for no-take reserves. Reviews in Fish Biology and Fisheries 15:129-154.
Borucinska, J., J. Martin, and G. Skomal. 2001. Peritonitis and pericarditis associated with gastric perforation by a retained fishing hook in a blue shark. Journal of Aquatic Animal Health 13:347-354.

Brett, J. R., and T. D. D. Groves. 1979. Physiological energetics. Pages 279-352 in W. S. Hoar, D. J. Randall, and J. R. Brett, editors. Fish physiology, volume 8: bioenergetics and growth. Academic Press, New York.

Carbines, G. D. 1999. Large hooks reduce catch-and-release mortality of blue cod Parpercis colias in the Marlborough Sounds of New Zealand. North American Journal of Fisheries Management 19:992-998.

Collett, D. 2003. Modelling survival data in medical research, 2nd edition. Chapman and Hall/CRC, New York.

Colvin, M. A. 1991. Evaluation of minimum-size limits and reduced daily limits on the crappie populations and fisheries in five large Missouri reservoirs. North American Journal of Fisheries Management 11:585-597.

Cooke, S. J., J. F. Steinmetz, J. F. Degner, E. C. Grant, and D. P. Philipp. 2003. Metabolic fright responses of different-sized largemouth bass (Microterus salmoides) to two avian predators show variations in nonlethal energetic costs. Canadian Journal of Fisheries and Aquatic Sciences 81:699-709.

Davis, M. W. 2002. Key principles for understanding fish bycatch discard mortality. Canadian Journal of Fisheries and Aquatic Sciences 59:1834-1843.

Davis, M. W., B. L. Olla, and C. B. Schreck. 2001. Stress induced by hooking, net towing, elevated sea water temperature and air in sablefish: lack of concordance between mortality and physiological measures of stress. Journal of Fish Biology 58:1-15.

Davis, M. W., and S. J. Parker. 2004. Fish size and exposure to air: potential effects on behavioral impairment and mortality rates in discarded sablefish. North American Journal of Fisheries Management 24:518-524.

Davis, M. W., and C. B. Schreck. 2005. Responses by Pacific halibut to air exposure: lack of correspondence among plasma constituents and mortality. Transactions of the American Fisheries Society 134:991-998.

Fleiss, J. L. 1981. Statistical methods for rates and proportions, 2nd edition. Wiley and Sons, New York.

Houston, A. H. 1990. Blood and circulation. Pages 273-334 in C. B. Schreck and P. B. Moyle, editors. Methods for fish biology. American Fisheries Society, Bethesda, Maryland.

Hueter, R. E., C. A. Manire, J. Tyminski, J. M. Hoenig, and D. A. Hepworth. 2006. Assessing mortality of released or discarded fish using a logistic model of relative survival derived from tagging data. Transactions of the American Fisheries Society 135:500-508.

Kiefer, J. D. 2000. Limits to exhaustive exercise in fish. Comparative Biochemistry and Physiology Part A 126:161-179.

Killen, S. S., C. D. Suski, S. J. Cooke, D. P. Philipp, and B. L. Tufts. 2006. Factors contributing to the physiological disturbance in walleyes during simulated live-release angling tournaments. Transactions of the American Fisheries Society 135:557-569.

Lupes, S. C., M. W. Davis, B. L. Olla, and C. B. Schreck. 2006. Capture-related stressors impair immune system 
function in sablefish. Transactions of the American Fisheries Society 135:129-138.

Malchoff, M. H. 1995. Effects of catch and release angling on important northeast marine fishes: mortality factors and applications to recreational fisheries. Final Project Report submitted to NOAA, Gloucester, Massachusetts.

Malchoff, M. H., and S. W. Heins. 1997. Short-term hooking mortality of weakfish caught on single-barb hooks. North American Journal of Fisheries Management 17:477-481.

Matlock, G. C., L. W. McEachron, J. A. Dailey, P. A. Unger, and P. Chai. 1993. Short-term hooking mortalities of red drums and spotted seatrout caught on single-barb and treble hooks. North American Journal of Fisheries Management 13:186-189.

Moyes, C. D., N. Fragoso, M. K. Musyl, and R. W. Brill. 2006. Predicting postrelease survival in large pelagic fish. Transactions of the American Fisheries Society 135:1389-1397.

Muoneke, M. I., and W. M. Childress. 1994. Hooking mortality: a review for recreational fisheries. Reviews in Fisheries Science 2:123-156.

Northeast Fisheries Science Center (NEFSC). 2005. 41st Northeast regional stock assessment workshop (41st SAW). 41st SAW Assessment Report. NEFSC Reference Document CRD 05-14, Woods Hole, Massachusetts.

Olla, B. L., M. W. Davis, and C. B. Schreck. 1997. Effects of simulated trawling on sablefish and walley pollock: the role of light intensity, net velocity and towing duration. Journal of Fish Biology 50:1181-1194.

Olla, B. L., M. W. Davis, and C. B. Schreck. 1998. Temperature magnified postcapture mortality in adult sablefish after simulated trawling. Journal of Fish Biology 53:743-751.
Priede, I. G. 1985. Metabolic scope in fishes. Pages 33-64 in P. Tytler and P. Calow, editors. Fish energetics: new perspectives. The Johns Hopkins Press, Baltimore, Maryland.

Quinn, G. P., and M. J. Keough. 2002. Experimental design and data analysis for biologists. Cambridge University Press, New York.

SAS Institute. 1996. SAS/STAT software: changes and enhancements through release 6.11. SAS Insitute, Cary, North Carolina.

Schramm, H. L., Jr., P. J. Haydt, and K. M. Portier. 1987. Evaluation of prerelease, postrelease, and total mortality of largemouth bass caught during tournaments in two Florida lakes. North American Journal of Fisheries Management 7:394-402.

Selvin, S. 1998. Modern applied biostatistical methods using S-Plus. Monographs in epidemiology and biostatistics, volume 28. Oxford University Press, New York.

Stunz, G. W., and D. A. McKee. 2006. Catch-and-release mortality of spotted seatrout in Texas. North American Journal of Fisheries Management 26:843-848.

Vaughan, D. S., and J. T. Carmichael. 2000. Assessment of Atlantic red drum for 1999: northern and southern regions. NOAA Technical Memorandum NMFS-SEFSC447.

Wedemeyer, G. A., B. A. Barton, and D. J. McLeay. 1990. Stress and acclimation. Pages 451-489 in C. B. Schreck and P. B. Moyle, editors. Methods for fish biology. American Fisheries Society, Bethesda, Maryland.

Williams, E. H. 1995. Survival of fish captured by hook and released. Master's thesis, University of Rhode Island, Kingston. 